\title{
Based on Damage Mechanics of Ladle Crane Dynamic Reliability Research
}

\author{
Xiaogang $\mathrm{Qu}^{*}{ }^{* 1,2}$, Gening $\mathrm{Xu}^{2}$ and Xiaoning $\mathrm{Fan}^{2}$ \\ ${ }^{I}$ School of Mechanical \& Electronical Engineering, Lanzhou University of Technology, Lanzhou 730050, China \\ ${ }^{2}$ College of Mechanical Engineering, Taiyuan University of Science and Technology, Taiyuan 030024, China
}

\begin{abstract}
Based on the damage mechanics theory, summarized a new dynamic reliability calculation method with explicit physical meaning, which is used for researching structural dynamic reliability on cyclic stress. By using of the model of stress-strength interference, ignoring the effects of erosion and aging on the strength degradation, only consider that the change of damage leads to the effective stress increasing. Take the intensity as a random variable, view stress as a random variable which was changed with the times of loading, combine physical experiments and simulation with sampling, analog the dynamic reliability curve of the casting crane hook on the beam with the change of loading times. Analyze the changing trends of dynamic reliability under the condition of different distribution parameters of cross section at the $420{ }^{\circ} \mathrm{C}$. The results suggested that the reliability showing a downward trend when the life is about $85 \%$, the dynamic reliability curve has a typical bathtub curve of the latter two steps.
\end{abstract}

Keywords: Casting crane, damage evolution model, damage mechanics, dynamic reliability, fatigue damage, stress strength interference.

\section{INTRODUCTION}

Under the circumstances of known stress and distribution of strength, the traditional reliability model is that the reliability is calculated directly by the stress strength interference theory. However, the reliability calculated is said to be the static reliability $[1,2]$. The research of dynamic reliability is more complicated than that of static reliability, Salvatore [3], Chaudhuri [4] have researched the dynamic reliability, but the influence of time to strength and stress was not considered in the analysis. Professor xieliyang in Dongbei university and zuoyongzhi in Tsinghua university have done much work about the research of dynamic reliability [5-8], but the law of strength degradation was hard to be got in the engineering applications. In the paper, with the traditional reliability calculation method and the damage mechanics theory, the dynamic reliability calculation method based on damage mechanics is summarized, this calculation method has the explicit physical background.

In the practical engineering, mechanical components and parts are influenced by many elements such as the environments, stress and strength are dynamic process, with the stretch of employing time, strength shows the tendency of degradation. So reliability quota is a dynamic and degressive process with the increase of time. The degradation of strength can be divided into two parts, the first part is some elements related to time, such as erosion and aging. The other part is the fatigue damage caused by cyclic load, which is related to many factors, such as loading times, loading sizes and loading frequency, etc.

SSI is the theory that has many applications, the interference area of distribution of random variable stress and random variable strength is the ineffective area. Strength is random process of time in the practical engineering, with the increase of loading times and loading time, strength tends to degradation. From Fig. (1), with the stretch of time, intersecting area increases gradually which leads to the decrease of reliability.

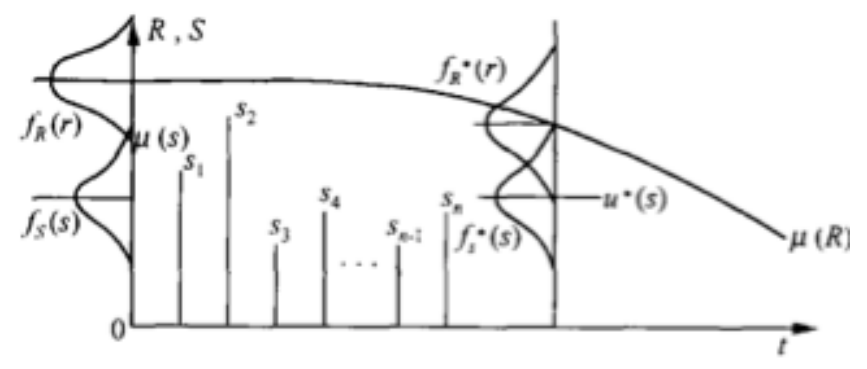

Fig. (1). Strength degradation trends change with time diagram.

The reason of degradation of strength is that defects and cracks appear inside of the material, because of materials in the Cyclic alternating stress, which results in decrease of mechanical property.

Damage value "D" is inferred by using of damage mechanical method, and effective stress is got by value"D"after damage, the process of effective stress increase is like the process of strength degradation, it increases with the stretch of loading times. On the assumption that strength degradation is caused by fatigue damage because of loading, and without consideration of 
strength influenced by erosion and aging, in other words it is the process of stress increase. From Fig. (2), with the stretch of time, stress and intersecting area increase gradually, finally reliability quota decrease gradually.

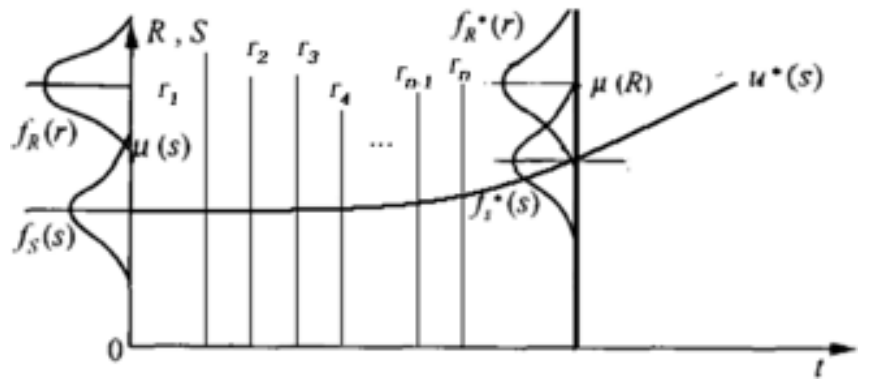

Fig. (2). Stress increases trends change with time diagram.

In the existing calculation method of dynamic reliability which not from the essence of material damage to describe the influence of loading times for structure reliability. But the theory of damage mechanics for load loading times how to affect the material mechanical properties with detailed description of the theory with the effective stress increase indirectly reflects the strength degradation, the application can use the theory to the stress strength interference theory, the very good solve the problem of the dynamic reliability analysis.

\section{FATIGUE DAMAGE THEORY}

According to damage mechanical theory [9], damage variable $\mathrm{D}$ stands for the expansion of microvoid and Micro cracks cause material in the process of damage real effective bearing area " $\tilde{A}$ " of the degree of decrease, namely, forming and extending of micro-cracks and micro-gaps makes crosssectional area " $A$ " of test specimens reduce to practical effective loaded area " $\tilde{A}$ ", and the diminution of effective loaded area results in the increase of practical stress, which leads to degradation of mechanical property of materials. According to the definition of damage mechanics assume:

$1-D=\tilde{A} / A$

reduced of the cross section effective bearing area,

Lead to the increase of effective stress, Effective stress can be expressed as:

$\tilde{\sigma}=\sigma /(1-D)$

The reason of the fatigue damage is the material below its ultimate strength under the alternating load, some local area or wide area first enter a state of yield, high degree of plastic deformation in a local region, it is a kind of the fracture process of its excellent transgranular fracture.

According to continual damage mechanics theory, fatigue damage is regarded to be expressed by dissipation potential function. To express the degree of damage accumulation :

$\phi=\frac{Y^{2}}{2 S_{0}} \frac{\dot{r}}{(1-D)^{a_{0}}}$

$S_{0} \longrightarrow$ Materials related to the temperature constant;

$a_{0} \_$material constant; $\dot{r} \_$each cycle of accumulated plastic strain;

the extent of damage accumulation is described by function $\beta(\sigma, T)$ instead of $a_{0}$, for experimental cyclic load is pulsation cycle, " $\sigma$ " expressed by the biggest stress " $\sigma_{\max }$ ", Expression (4) is written as:

$\phi=\frac{Y^{2}}{2 S_{0}} \frac{\dot{r}}{(1-D)^{1-k\left(\sigma_{\max }, T\right)}}$

On the assumption that plasticity deformation leads to interior damage and energy consumption, so dissipation potential function is expressed by :

$\phi=\phi_{P}\left(\sigma, \sigma_{Y}, R, D\right)+\phi_{D}\left(Y, r, T, \varepsilon_{e}, D\right)$

$\sigma \_$_tress tensor;

$\sigma_{Y}-$ Material the initial yield stress;

$\mathrm{R}$ - Isotropic cumulative plastic strain hardening parameters;

$\mathrm{Y} \_$- strain energy release rate;

$\mathrm{r}$ - accumulated plastic strain ;

$\mathrm{T}$ — absolute temperature;

$\varepsilon_{e}-$ Elastic strain tensor ;

$\phi_{P} \_$Elastic strain tensor, In view of the loss of plastic parts;

$\phi_{D} \longrightarrow$ Dissipation part of the damage;

In view of the damage dissipation part $\phi_{D}$, Damage kinetics law can be expressed as:

$\dot{D}=-\frac{\partial \phi_{D}}{\partial Y} \dot{\lambda}=-\frac{\partial \phi}{\partial Y}$

Will type (4) into type (6) obtain (7)

$\dot{D}=\left(-\frac{Y}{S_{0}}\right) \frac{\Delta \dot{r}}{(1-D)^{1-k\left(\sigma_{\max }, T\right)}}$

strain energy release rate:

$Y=-\frac{\sigma_{e q}^{2}}{2 E(1-D)^{2}} R_{V}$

Put forward by Lemaitre strain equivalence principle, $\tilde{\sigma}=\frac{\sigma}{1-D}$, Von Mises equivalent stress can be expressed as $\Delta \tilde{\sigma}_{e q}=\frac{\sigma_{e q}}{1-D}$, Based on the strain equivalence hypothesis, The stress-strain relations are represented as:

$\Delta \tilde{\sigma}_{e q}=K \Delta r^{m}$

$\mathrm{K}, \mathrm{m}-$ constant

Will type (8), (9) into type (7)

$\dot{D}=\left(-\frac{K^{2} R_{V}}{2 E S_{0}}\right) \frac{\Delta r^{2 m}}{[(1-D)]^{1-\mathrm{k}\left(\sigma_{\max }, T\right)}} \Delta \dot{r}$ 
Integral type (10), order $D=N / N_{f}$, Generation into the boundary conditions $\left.D\right|_{N=N_{0}}=D_{0},\left.D\right|_{N=N_{f}}=1$

$D=1-\left(1-D_{0}\right)\left[\left(1-N / N_{f}\right)\right]^{\mathrm{k}\left(\sigma_{\max }, T\right)}$

Type (11) is deduced based on damage mechanics theory of fatigue damage evolution model.

\section{STRESS STRENGTH INTERFERENCE THEORY}

The stress that product bears exceeds the strength of material, so the product loses effectiveness, stress exceeds yield stress, material yield occurs, stress exceeds the limitation of strength, crack appears. The strength of product is different with different material characters, structures and producing process and the size of strength can be expressed by a random variable, the size of stress that product bears is a random variable. In the random time of normal working process, the strength is always bigger than the stress, once the stress exceeds the strength, the product will lose effectiveness. This is SSI. Strength stands for the biggest stress ability that the product bears. According to ineffective process, reliable analysis can be proceeded by analyzing interaction between product stress and strength.

The stress strength interference model functions:

$M=R-S$

$R$ - The intensity of specimen

$S$ - The stress on the specimen

$\mathrm{R}, \mathrm{S}$ Contains the function of many variables

$R=R(\mathrm{X})=\mathrm{R}\left(\mathrm{X}_{1}, \mathrm{X}_{2}, \cdots, \mathrm{X}_{n}\right), S=S(Y)=\mathrm{R}\left(Y_{1}, Y_{2}, \cdots, Y_{n}\right)$ 。

Functions are expressed as:

$M=R-S=f(\mathrm{X}, \mathrm{Y})=f\left(\mathrm{X}_{1}, \mathrm{X}_{2}, \cdots, \mathrm{X}_{n}, \mathrm{Y}_{1}, \mathrm{Y}_{2}, \cdots, \mathrm{Y}_{n}\right)$

\section{APPLICATION OF DAMAGE MECHANICS IN SSI (STRESS STRENGTH INTERFERENCE)}

In the traditional SSI, the strength and stress of components are all static random variable, the distribution has nothing to do with time, in fact, under the effect of stress, strength of test specimen will degrade gradually with the increase of using time, because of fatigue, erosion and aging. The degradation of product strength is a random process in the continual state. In this paper, the degradation of product strength consists of two parts, the first part of strength degradation is Fatigue and creep damage caused by cyclic stress, the second part is degradation of strength caused by environmental erosion and aging. In the first part, according to explanation of damage mechanics theory, in the material loading process, the fatigue cracks in part of material caused by fatigue damage and grain boundary hole in material interior created by creep damage lead to the decrease of effective loading area of section, so the effective stress increase, finally, the strength degrades.

SSI functions should be expressed as:

$M=R-S\left(D_{N}\right)$
According to the damage evolution equation type (11), Cumulative damage function is the function of loading times, with the increase of loading times, damage tends to increase. In pulsation cyclic loading, Damage value " $\mathrm{D}$ " is related to initial damage, stress level and temperature, so (14) should be corrected:

$M=R-\tilde{S}\left(N, D_{0}, \mathrm{~T}, \sigma_{\max }\right)$

The temperature $\mathrm{T}$ not only influences damage $\mathrm{D}$, For Q345, with the increase of temperature, the yield strength $\sigma_{S}$ , ultimate strength $\sigma_{\mathrm{b}}$ also showed a trend of decline. Therefore, strength should also is a function of temperature T, Write type (15):

$$
M=R(\mathrm{~T})-\tilde{S}\left(N, D_{0}, \mathrm{~T}, \sigma_{\max }\right)
$$

Type (16) is the theories of damage mechanics on the stress strength interference model

\section{EXPERIMENT RESULT ANALYSIS}

The test material is Q345 which is commonly used in crane, test conditions for stress control, pulsation cycle, Sine wave load. Before the test, keep samples in the furnace for 30 minute. The environment is atmospheric for laboratory. The load frequency $\mathrm{f}=0.3 \mathrm{~Hz}$ when have stretch meter, the load frequency $\mathrm{f}=4 \mathrm{~Hz}$ when haven't stretch meter. At the same temperature $420^{\circ} \mathrm{C}$ under different stress level and the same stress level $(0 \sim 480 \mathrm{MPa})$ Cycling test under different temperature between $15^{\circ} \mathrm{C}$ and $420^{\circ} \mathrm{C}$.

5.1 .The Analysis of the Experimental Data Under the Same Stress Level $(0 \sim 480 \mathrm{MPa})$ and the Different Temperature

By the data can be seen in Table 1, the Stress cycle life maximizing at $300{ }^{\circ} \mathrm{C}$, Now in 300 , with two curve fitting in $15-420^{\circ} \mathrm{C}$, the fitting results as shown in Figs. (3-5).

\subsubsection{Damage Model in $15-300^{\circ} \mathrm{C}$}

$k=0.0335 e^{0.0048 T}$

$\mathrm{R} 2=0.959$

$D=1-\left(1-D_{0}\right)\left(1-N / N_{f}\right)^{0.0335 e^{0.0048 T}}$

5.1.2. Damage model in $300-420^{\circ} \mathrm{C}$

$k=0.9143 e^{-0.0083 T}$

$D=1-\left(1-D_{0}\right)\left(1-N / N_{f}\right)^{0.9143 e^{-0.0083 T}}$

$\mathrm{R} 2=0.9897$

5.2. The Test Data of the Same Temperature $420{ }^{\circ} \mathrm{C}$ Under Different Stress Level as Shown in Table 2

$k=2.2514 e^{-0.0091 \sigma_{\max }}$
$\mathrm{R} 2=0.8845$
$D=1-\left(1-D_{0}\right)\left(1-N / N_{f}\right)^{2.2514 e^{-0.0091 \sigma_{\max }}}$ 
Table 1. Same stress level (0-480 MPa) data at different temperatures.

\begin{tabular}{|c|c|c|c|c|}
\hline $\begin{array}{ll}\text { Test Specimen } & \text { Parameter } \\
\end{array}$ & $D_{0}$ & $\boldsymbol{k}$ & $N_{f} /$ Cycle & $T /{ }^{\circ} \mathrm{C}$ \\
\hline 1 & 0 & 0.03993 & 2571 & 15 \\
\hline 2 & 0.0206 & 0.04994 & 3024 & 100 \\
\hline 3 & 0.0108 & 0.07548 & 24792 & 200 \\
\hline 4 & 0.0174 & 0.12222 & 61192 & 250 \\
\hline 5 & 0.0198 & 0.01528 & 287366 & 300 \\
\hline 6 & 0.0115 & 0.04036 & 84104 & 375 \\
\hline 7 & 0.0168 & 0.03173 & 38875 & 400 \\
\hline 8 & 0.0104 & 0.02779 & 8341 & 420 \\
\hline
\end{tabular}

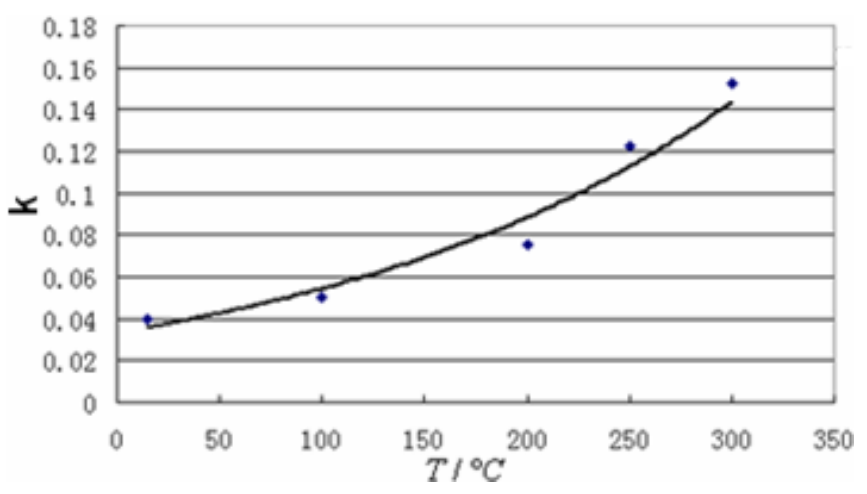

Fig. (3). T and k curve fitting at $1500-300{ }^{\circ} \mathrm{C}$.

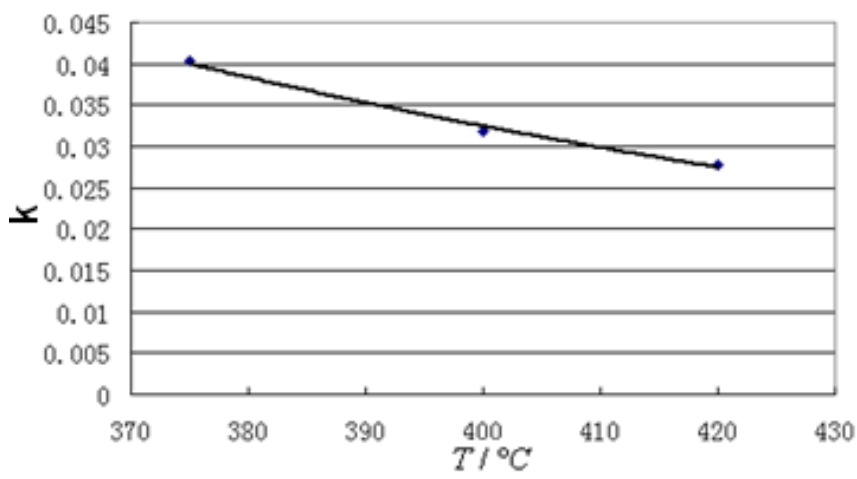

Fig. (4). $\mathrm{T}$ and $\mathrm{k}$ curve fitting at $300-420^{\circ} \mathrm{C}$.

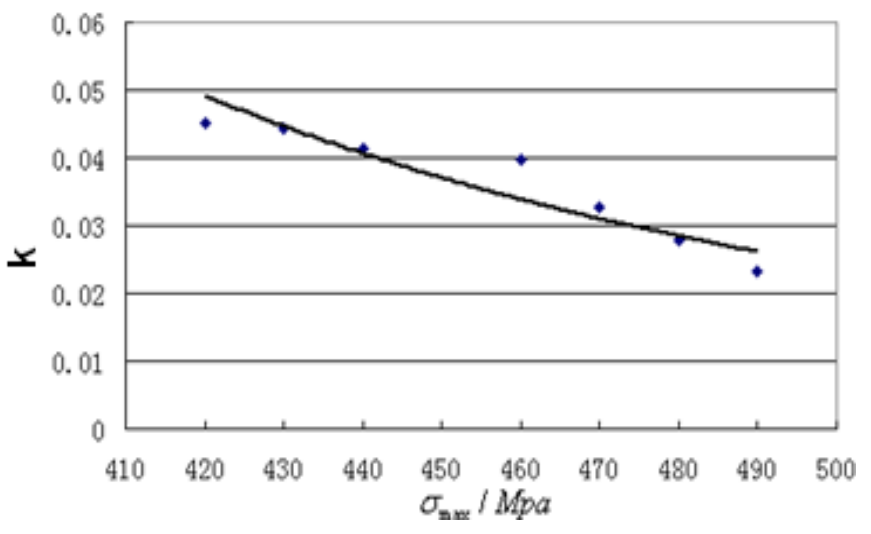

Fig. (5). $\sigma_{\max }$ and $\mathrm{k}$ curve fitting at $300-420^{\circ} \mathrm{C}$.

5.3. 16 MnR Mechanics Performance Test Data at Different Temperatures

The ultimate strength and temperature fitting function relation:

$$
\begin{aligned}
\sigma_{\mathrm{b}}= & 4.072192199248056 \times 10^{-10} T^{5} \\
& \quad-4.412721256265577 \times 10^{-7} T^{4} \\
+ & 1.544129660087676 \times 10^{-4} T^{3}-0.01717947799185 T^{2} \\
-0.17836192042617 T+5.912730263157935 \times 10^{2} & \\
\text { R2 }= & 0.9671
\end{aligned}
$$

Table 2. Different stress levels of test data at $420{ }^{\circ} \mathrm{C}$.

\begin{tabular}{|c|c|c|c|c|}
\hline Specimen & & $\boldsymbol{k}$ & $\boldsymbol{N}_{f} /$ Cycle & $\boldsymbol{\sigma}_{\text {max }} / \mathbf{M}$ Pa \\
\hline \hline 1 & 0.0134 & 0.04525 & 320614 & $0 \sim 420$ \\
\hline 2 & 0.0036 & 0.04438 & 238362 & $0 \sim 430$ \\
\hline 3 & 0.0262 & 0.04136 & 144743 & $0 \sim 440$ \\
\hline 4 & 0.0142 & 0.03963 & 91863 & $0 \sim 460$ \\
\hline 5 & 0.0307 & 0.0328 & 27302 & $0 \sim 470$ \\
\hline 6 & 0.0104 & 0.02779 & 8341 & $0 \sim 480$ \\
\hline 7 & 0 & 0.02319 & 2188 & $0 \sim 490$ \\
\hline
\end{tabular}


Analysis of the data in Table 3, the yield strength and ultimate strength decreased with increased temperature, the fitting results as shown in Fig. (6).

Table 3. Different temperature and yield strength/ultimate strength test data.

\begin{tabular}{|c|c|c|c|}
\hline Temperature $/{ }^{\circ} \mathbf{C}$ & $\sigma_{\boldsymbol{S}} / \mathbf{M P a}$ & $\boldsymbol{\sigma}_{\mathrm{b}} / \mathbf{M P a}$ & $\boldsymbol{\varphi} / \boldsymbol{\%}$ \\
\hline \hline 20 & 378 & 582 & 58 \\
\hline 100 & 312 & 516 & 63 \\
\hline 200 & 319 & 528 & 56 \\
\hline 300 & 283 & 576 & 52 \\
\hline 400 & 233 & 527 & 63 \\
\hline 420 & 238 & 517 & 70.5 \\
\hline
\end{tabular}

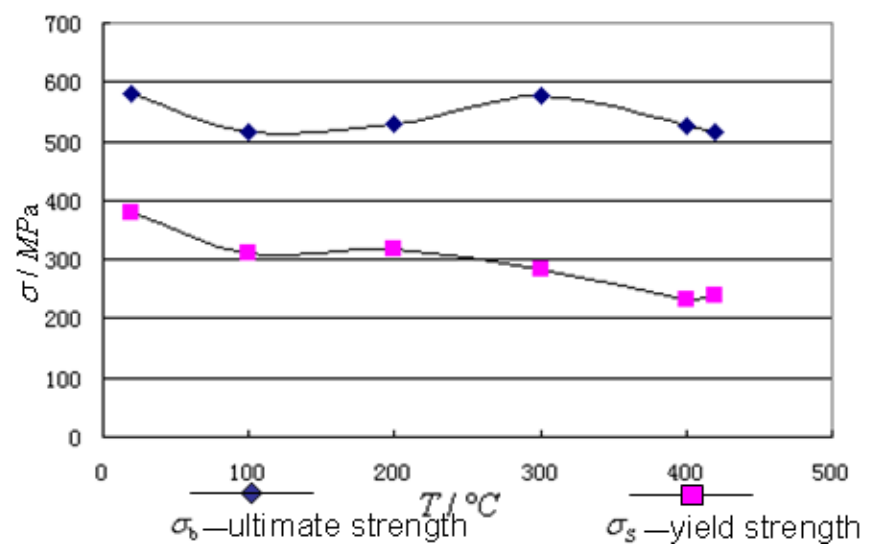

Fig. (6). Different temperature and yield strength/ultimate strength curve fitting.

\section{INSTANCE ANALYSIS}

Analysis object for ladle crane beams on the hook, the hook beams by using the box beam cross section, the structure of section as shown in Fig. (7), mechanical model as shown in Fig. (8).

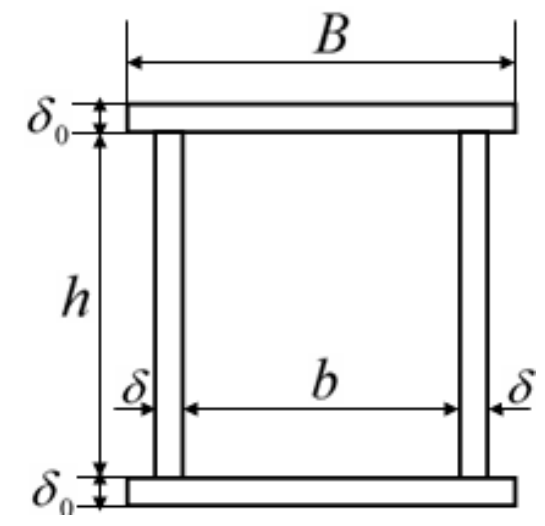

Fig. (7). Cross section of the hook on the beam.

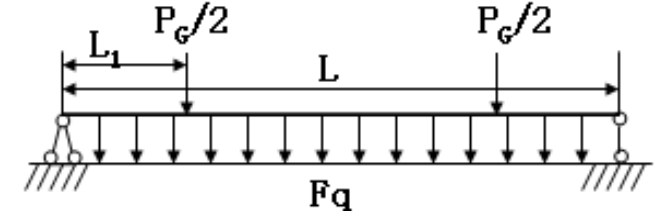

Fig. (8). mechanical model of the hook on the beam.

The bending stress calculation

$M=\frac{F_{q} L^{2}}{8}+\frac{P_{Q}}{2} L_{1}$

$F_{q} \_$Hook on the beam weight per unit length

$P_{Q} \longrightarrow$ Hoisting load

$L-$ Hook on the beam length

$F_{q}=\sigma A g$

$A=2 B \delta_{0}+2 h \delta$

$A-$ Cover plate width

$\delta_{0}$ - The thickness of the plate

$h$-web plate height

$\delta$-web plate thickness

$\sigma \_\mathrm{Q} 345$ density $\left(\sigma=7850 \mathrm{~kg} / \mathrm{m}^{3}\right)$

moment of inertia of cross-section:

$I_{x}=2\left[\frac{\delta}{12} h^{3}+\frac{B \delta_{0}^{3}}{12}+\frac{B \delta_{0}}{4}\left(h+\delta_{0}\right)^{2}\right]$

$\delta$ - web plate thickness

$\delta_{0} \longrightarrow$ The thickness of the plate

$h$ _-web plate height

For the stress calculation expression

$S=\frac{M \times y}{I}$

$I-$ moment of inertia of cross-section

$y$-abdomen board away from neutral axis

Combination type (2) and type (25)

$\tilde{S}=S /(1-D)=\frac{M \times y}{I} /(1-D)$

Then type (11) into type (26)

$\tilde{S}=S /\left(1-D_{0}\right)\left(1-N / N_{f}\right)^{k\left(\sigma_{\max }, T\right)}$

$=\frac{M \times y}{I} /\left(1-D_{0}\right)\left(1-N / N_{f}\right)^{k\left(\sigma_{\max }, T\right)}$

Combination type (17), type (21) and type (26):

$M=R(\mathrm{~T})-\tilde{S}\left(N, D_{0}, \mathrm{~T}, \mathrm{~F}_{q}, P_{G}, \mathrm{~b}, \mathrm{~B}, \delta, \delta_{0}, \mathrm{~h}, \mathrm{~L}, \mathrm{~L}_{1}\right)$ 
Table 4. Distribution parameter of the standard deviation is 0.1 times of the average.

\begin{tabular}{|c|c|c|}
\hline Distribution Parameter & Mean Value & Standard Deviation \\
\hline \hline Sectional Dimension & $\mu_{P_{G}}=180000 \mathrm{kN}$ & $\sigma_{P_{G}}=9000 \mathrm{kN}$ \\
\hline Hoisting load/PG & $\mu_{L}=3000 \mathrm{~mm}$ & $\sigma_{L}=300 \mathrm{~mm}$ \\
\hline Hook on the beam length/L & $\mu_{L_{1}}=2600 \mathrm{~mm}$ & $\sigma_{L_{1}}=260 \mathrm{~mm}$ \\
\hline Hook plate spacing/L1 & $\mu_{\delta}=8 \mathrm{~mm}$ & $\sigma_{\delta}=0.8 \mathrm{~mm}$ \\
\hline web thickness $/ \delta$ & $\mu_{h}=800 \mathrm{~mm}$ & $\sigma_{h}=80 \mathrm{~mm}$ \\
\hline Web height $/ h$ & $\mu_{\delta_{0}}=16 \mathrm{~mm}$ & $\sigma_{\delta_{0}}=1.6 \mathrm{~mm}$ \\
\hline cover board thickness $/ \delta_{0}$ & $\mu_{B}=600 \mathrm{~mm}$ & $\sigma_{B}=60 \mathrm{~mm}$ \\
\hline Cover plate width/B & $\mu_{D_{0}}=0.013$ & $\sigma_{D_{0}}=0.00065$ \\
\hline initial damage/D0 & $\mu_{R}=517 \mathrm{MPa}$ & $\sigma_{R}=25.85 \mathrm{MPa}$ \\
\hline Intensity $/ R$ & & \\
\hline
\end{tabular}

Type (27) is the hook on the beam on the dynamic stress strength interference model.

The random variables are assumed to be normal distribution as shown in Tables 4-7. Analysis of hook beam under the condition of temperature $420^{\circ} \mathrm{C}$, hoisting load 180 tons, and section size different standard deviation, the reliability of change with load frequency sampling test.

Standard deviation is 0.1 times the average of the dimensional parameters dynamic reliability degradation curve.

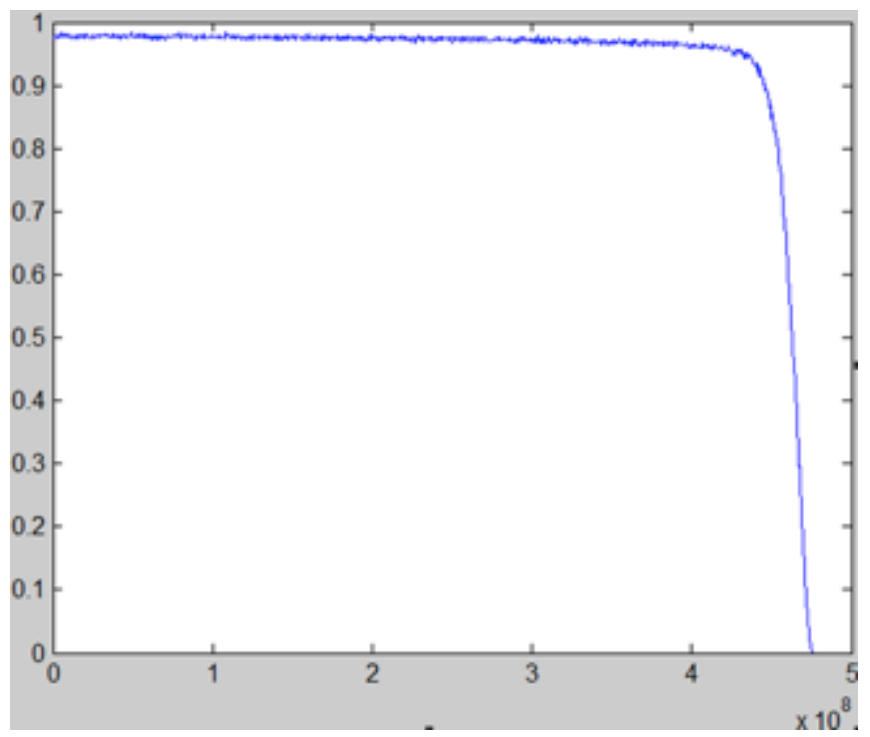

Fig. (9). Reliability degradation curve under the condition of the standard deviation is 0.1 times of the average.

Standard deviation is 0.05 times the average of the dimensional parameters dynamic reliability degradation curve.

By sampling test results can be seen in Figs. $(\mathbf{9}, \mathbf{1 0})$, when the cross section size parameters of the standard deviation is 0.1 times the average, Reliability decline significantly when compared with the standard deviation is 0.05 times the average. But the same is at the beginning of the loading cycle, the reliability degree of decline in relatively flat, around $85 \%$ in life, a sharp drop in reliability. Using damage mechanics to explain, with the increase of loading number, a new micro crack appeared in the interior of the metal structure, the existing micro crack development as the macro crack, results in the decrease of area of effective bearing structure. When macro crack appeared, Due to the crack tip stress concentration phenomenon, makes the crack propagation speed, to further weaken the structure bearing capacity.

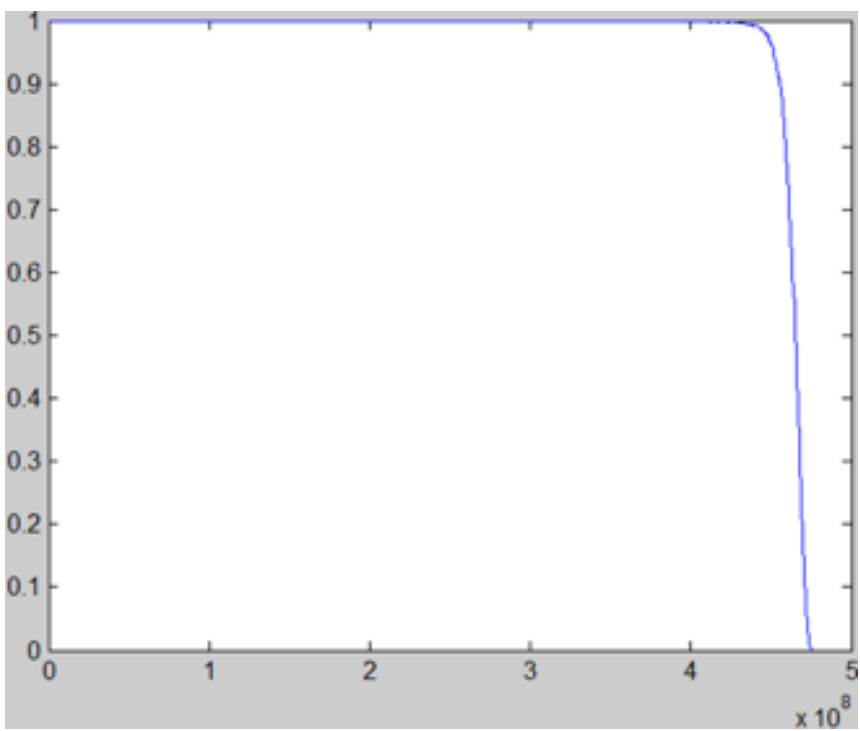

Fig. (10). Reliability degradation curve under the condition of the standard deviation is 0.05 times of the average.

The random variables are assumed to be normal distribution, Analysis of hook beam under the condition of temperature $420{ }^{\circ} \mathrm{C}$, hoisting load 180 tons, and changing web height and plate width, The reliability of change with load frequency sampling test. 
Table 5. Distribution parameter of the standard deviation is 0.05 times of the average.

\begin{tabular}{|c|c|c|}
\hline Dectional Dimension & Mean Value & Standard Deviation \\
\hline \hline Hoisting load/PG & $\mu_{P_{G}}=180000 \mathrm{kN}$ & $\sigma_{P_{G}}=9000 \mathrm{kN}$ \\
\hline Hook on the beam length/L & $\mu_{L}=3000 \mathrm{~mm}$ & $\sigma_{L}=150 \mathrm{~mm}$ \\
\hline Hook plate spacing/L1 & $\mu_{L_{1}}=2600 \mathrm{~mm}$ & $\sigma_{L_{1}}=130 \mathrm{~mm}$ \\
\hline web thickness $/ \delta$ & $\mu_{\delta}=8 \mathrm{~mm}$ & $\sigma_{\delta}=0.4 \mathrm{~mm}$ \\
\hline Web height $/ h$ & $\mu_{h}=800 \mathrm{~mm}$ & $\sigma_{h}=40 \mathrm{~mm}$ \\
\hline cover board thickness $/ \delta_{0}$ & $\mu_{\delta_{0}}=16 \mathrm{~mm}$ & $\sigma_{\delta_{0}}=0.8 \mathrm{~mm}$ \\
\hline Cover plate width $/ \mathrm{B}$ & $\mu_{B}=600 \mathrm{~mm}$ & $\sigma_{B}=30 \mathrm{~mm}$ \\
\hline initial damage $/ \mathrm{D}_{0}$ & $\mu_{D_{0}}=0.013$ & $\sigma_{D_{0}}=0.00065$ \\
\hline Intensity $/ R$ & $\mu_{R}=517 \mathrm{MPa}$ & $\sigma_{R}=25.85 \mathrm{MPa}$ \\
\hline
\end{tabular}

Table 6. The distribution parameter when the height of web increase $20 \mathrm{~mm}$.

\begin{tabular}{|c|c|c|}
\hline Distribution Parameter & Mean Value & Standard Deviation \\
\hline \hline Sectional Dimension & $\mu_{P_{G}}=180000 \mathrm{kN}$ & $\sigma_{P_{G}}=9000 \mathrm{kN}$ \\
\hline Hoisting load/PG & $\mu_{L}=3000 \mathrm{~mm}$ & $\sigma_{L}=300 \mathrm{~mm}$ \\
\hline Hook on the beam length/L & $\mu_{L_{1}}=2600 \mathrm{~mm}$ & $\sigma_{L_{1}}=260 \mathrm{~mm}$ \\
\hline Hook plate spacing/L1 & $\mu_{\delta}=8 \mathrm{~mm}$ & $\sigma_{\delta}=0.8 \mathrm{~mm}$ \\
\hline web thickness $/ \delta$ & $\mu_{h}=820 \mathrm{~mm}$ & $\sigma_{h}=82 \mathrm{~mm}$ \\
\hline Web height $/ h$ & $\mu_{\delta_{0}}=16 \mathrm{~mm}$ & $\sigma_{\delta_{0}}=1.6 \mathrm{~mm}$ \\
\hline cover board thickness $/ \delta_{0}$ & $\mu_{B}=600 \mathrm{~mm}$ & $\sigma_{B}=60 \mathrm{~mm}$ \\
\hline Cover plate width/B & $\mu_{D_{0}}=0.013$ & $\sigma_{D_{0}}=0.00065$ \\
\hline initial damage/ $/ \mathrm{D}_{0}$ & $\mu_{R}=517 \mathrm{MPa}$ & $\sigma_{R}=25.85 \mathrm{MPa}$ \\
\hline Intensity $/ R$ & ${ }_{2}$ & \\
\hline
\end{tabular}

Web height increase $20 \mathrm{~mm}$ dynamic reliability degradation curve.

Cover plate width $20 \mathrm{~mm}$ increase in dynamic reliability degradation curve.

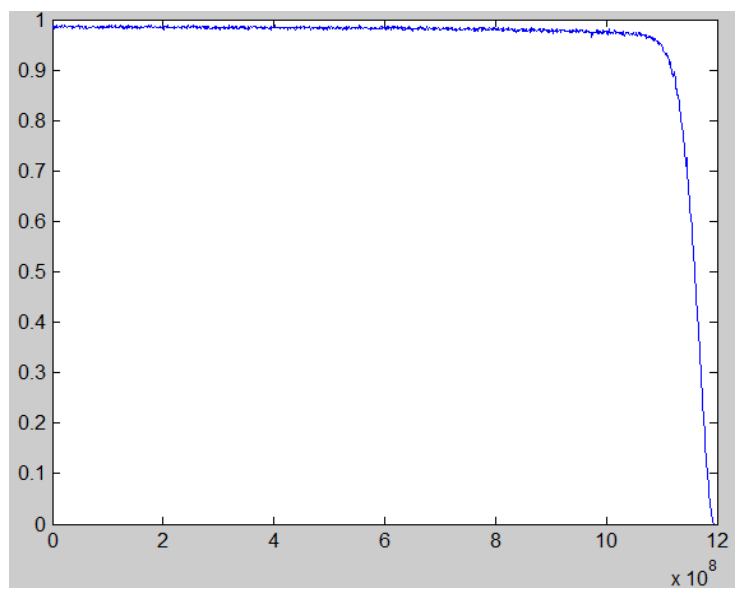

Fig. (11). The reliability degradation curve when the height of web increase $20 \mathrm{~mm}$.
By sampling test results analysis in Figs. $(11,12)$, change web height compared to the plate width can significantly affect the reliability. When the web height increase $20 \mathrm{~mm}$, dynamic reliability curve inflection point in a $10.8 \times 108$ cycles, and when the plate width increase $20 \mathrm{~mm}$, dynamic reliability curve inflection point in a $5.1 \times 108$ cycles, because web height changes than the plate width for the influence of moment of inertia. But the reliability curve of the inflection point also appeared in the life of $85 \%$.

\section{CONCLUSION}

The dynamic reliability research about Ladle crane beams on the hook of material Q345 was made in this paper. SSI model and dynamic reliability calculation based on damage mechanics theory were put forward. The following conclusions are made by the combination of fatigue experiments with reliable sampling experiments. 
Table 7. Distribution parameter when the width of cover plate increase $20 \mathbf{~ m m}$.

\begin{tabular}{|c|c|c|}
\hline Distribution Parameter & Mean Value & Standard Deviation \\
\hline \hline Hectional Dimension & $\mu_{P_{G}}=180000 \mathrm{kN}$ & $\sigma_{P_{G}}=9000 \mathrm{kN}$ \\
\hline Hook on the beam length/L & $\mu_{L}=3000 \mathrm{~mm}$ & $\sigma_{L}=300 \mathrm{~mm}$ \\
\hline Hook plate spacing/L1 & $\mu_{L_{1}}=2600 \mathrm{~mm}$ & $\sigma_{L_{1}}=260 \mathrm{~mm}$ \\
\hline web thickness $/ \delta$ & $\mu_{\delta}=8 \mathrm{~mm}$ & $\sigma_{\delta}=0.8 \mathrm{~mm}$ \\
\hline Web height $/ \mathrm{h}$ & $\mu_{h}=800 \mathrm{~mm}$ & $\sigma_{h}=80 \mathrm{~mm}$ \\
\hline cover board thickness $/ \delta_{0}$ & $\mu_{\delta_{0}}=16 \mathrm{~mm}$ & $\sigma_{\delta_{0}}=1.6 \mathrm{~mm}$ \\
\hline Cover plate width $/ \mathrm{B}$ & $\mu_{B}=620 \mathrm{~mm}$ & $\sigma_{B}=62 \mathrm{~mm}$ \\
\hline initial damage/ $/ \mathrm{D}_{0}$ & $\mu_{D_{0}}=0.013$ & $\sigma_{D_{0}}=0.00065$ \\
\hline Intensity $/ R$ & $\mu_{R}=517 \mathrm{MPa}$ & $\sigma_{R}=25.85 \mathrm{MPa}$ \\
\hline
\end{tabular}

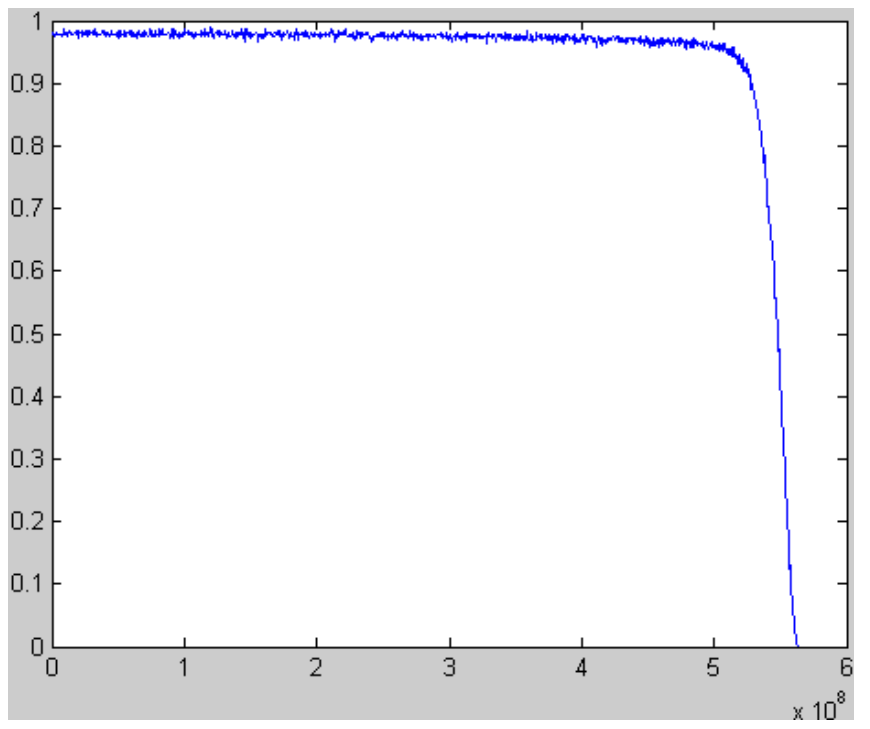

Fig. (12). The reliability degradation curve when the width of cover plate increase $20 \mathrm{~mm}$.

(1) The dynamic reliability is calculated by the combination of SSI with the damage mechanics theory, and under the direction of physical experiments, the dynamic reliability research has the explicit physical significance.

(2) In the physical experiments and sampling simulation experiments, to decrease the size of hook beam cross section on the standard deviation, significantly improve the structural reliability, it can be seen that changed web height compared to the plate width can significantly improve the reliability of structure, the same is the various test results, around $85 \%$ in life, casting crane hook beam reliability are presented on the obvious downward trend.
(3) Physical experimental data are limited, so reliable computational accuracy is expected to be improved. In the future, with the abundance of experimental data, computational accuracy will be enhanced.

\section{CONFLICT OF INTEREST}

The authors confirm that this article content has no conflict of interest.

\section{ACKNOWLEDGEMENTS}

This project is supported by National Natural Science Foundation of China (Grant No. 51275329), and Youth Fund Program of Taiyuan University of Science and Technology (20113014).

\section{REFERENCES}

[1] R.D. Tanmoyd, "A discretizing approach for evaluating reliability of complex systems under stress - strength model," IEEE Transaction on Reliability, vol. 50, no. 2, pp. 145-150, 2001.

[2] Z. Sun, Y. L. Chen, Y. Zhang, and J. Ding, "Reliability model of mechanical transmission system," Dongbei Daxue Xuebao/Journal of Northeastern University, vol. 24, no. 6, pp. 548 -551, 2003.

[3] B. Salvatore, C. Livia, and G. Francesco, "A multicriterion design of steel frames with shakedown constraints," Computers and Structures, no. 84, pp. 269-282, 2006.

[4] A. Chaudhuri, and S. Chakraborty, "Reliability evaluations of 3-d frame subjected to non-stationary earthquake," Journal of Sound and Vibration, vol. 295, no. 4, pp. 797-808, 2003.

[5] Z. Wang, L. Xie, and B. Li, "Time-dependent reliability model of component under random load," Journal of Mechanical Engineering, vol. 43, no. 12, pp. 20-25, 2007.

[6] Z. Wang, and L. Xie, "Time-dependent reliability model and failure rate analysis of mechanical components," Dongbei Daxue Xuebao/Journal of Northeastern University, vol. 28. no. 11, pp. 188-193, 2007. 
[7] Z. Wang, L. Xie, and B. Li, "Time-dependent reliability modeling and study of early failure rate for component," Hangkong Xuebao/Acta Aeronautica et Astronautica Sinica, vol. 28, no. 6, pp. 1379-1382, 2007.
[8] Y. Zuo, and X. Liu, "Fully stochastic analysis method for structural dynamic reliability," Journal of Tsinghua University (Science and Technology), vol. 44, no. 3, pp. 29-38, 2004.

[9] S. Yu, and X. Feng, "Damage Mechanics," Tsinghua University Press, vol. 12, no. 1, 1997, pp. 48-54.

Received: January 8, 2015

(C) Qu et al.; Licensee Bentham Open.

This is an open access article licensed under the terms of the Creative Commons Attribution Non-Commercial License (http://creativecommons.org/licenses/by-nc/3.0/) which permits unrestricted, non-commercial use, distribution and reproduction in any medium, provided the work is properly cited. 